\title{
Iconoclash: reflexões sobre cultura visual e pesquisas em Educação
}

\author{
Iconoclash: reflecting about visual culture and research in Education
}

Iconoclash: reflexiones sobre la cultura visual y las investigaciones sobre Educación

\author{
GUSTAVO E. FISCHMAN* \\ SANDRA R. SALES ${ }^{* *}$
}

\begin{abstract}
RESUMO - As sociedades contemporâneas demandam a capacidade de compreender e seguir regras implícitas da cultura visual, as quais são desenvolvidas por meio de múltiplas, heterogêneas e, frequentemente, efêmeras imagens. Este fenômeno tem sido denominado "virada pictórica". Este artigo aponta a discutir que: os efeitos da virada pictórica parecem ser mais limitados no campo da pesquisa em Educação; a ausência substancial dos fenômenos da cultura visual na pesquisa pedagógica, bem como a subutilização das ferramentas das metodologias da pesquisa visual, não se sustentam em barreiras epistemológicas. Propõe-se a pesquisar os fenômenos educativos a partir da perspectiva do iconoclash, analisando imagens sobre Ação Afirmativa publicadas na revista Veja durante o período 1995-2010. A investigação reconhece a constante presença da tensão no par imagem/significado.
\end{abstract}

Palavras-chave - Cultura visual. Pesquisa em educação. Virada pictórica.

ABSTRACT - Contemporary societies require the ability to understand and follow implicit rules of visual culture, which are developed through multiple, heterogeneous and often ephemeral images. This phenomenon has been named as the "pictorial turn". This article aims to discuss the following: the effects of the "pictorial turn" seem to be more limited in the field of research in education, the substantial absence of phenomena of visual culture in educational research, as well as the underutilization of the tools of visual research methodologies, is not based on epistemological barriers. We propose to investigate educational phenomena from the perspective of iconoclash, analyzing images of Affirmative Action published in Veja a weekly magazine during the period 1995-2010. We conclude by recognizing the unavoidability of the constant tension between the pair image/meaning.

Keywords - Visual culture. Educational research. Pictorial turn.

RESUMEN - Las sociedades contemporáneas requieren la capacidad de entender y seguir las reglas implícitas de la cultura visual, las cuales se desarrollan a través de numerosas, heterogéneas, ya menudo efímeras imágenes. Este fenómeno se ha denominado como el "giro pictórico". Este artículo tiene como objetivo discutir los siguientes puntos: los efectos de giro pictórico parece ser más limitada en el campo de la investigación en la educación; la ausencia sustancial de los fenómenos de la cultura visual en la investigación de la educación, así como la infrautilización de las herramientas de las metodologías de investigación visual, no parece relacionarse con los obstáculos epistemológicos. Se propone investigar fenómenos educativos desde la perspectiva de Iconoclash analizando las imágenes sobre las políticas de acción afirmativa que la revista Veja publicó durante el período 1995-2010. Concluimos reconociendo la presencia constante de la tensión entre imagén/significado.

Palabras clave - Cultura visual. Investigación educativa. Giro pictórico.

\footnotetext{
*Doutor em Ciências Sociais e Educação Comparada pela Universidade da Califórnia (Los Angeles, CA, Estados Unidos da América) e professor na Universidade Estadual do Arizona (Temp, AZ, Estados Unidos da América).E-mail: <gustavo.fischman@mac.com>.

**Doutora em Educação pela Universidade do Estado do Rio de Janeiro (Rio de Janeiro, RJ, Brasil) e professora na Universidade Federal Rural do Rio de Janeiro (Seropédica, RJ, Brasil).E-mail: <sandrareginasales@gmail.com>.
} 


\section{INTRODUÇÃO ${ }^{1}$}

$\mathrm{O}$ crescente interesse de estudos acadêmicos sobre experiências visuais segue uma indiscutível dinâmica: as imagens se tornaram onipresentes e mediações potentes na circulação dos signos, símbolos e informação. Como afirma Susan Buck-Morss (2004), o presente "se distingue de todos os séculos anteriores porque tem deixado um rastro fotográfico. Aquilo que se vê apenas uma vez e se registra, pode ser percebido/revisto quando e por quem quiser. A história se torna a singularidade compartilhada de um evento" (p. 23). Muitas atividades e eventos do cotidiano, tais como usar a Internet, assistir a filmes e a programas de televisão, participar de videoconferência e até mesmo contemplar vitrines, se transformaram em experiências-chave da "cultura visual" da modernidade urbana. As sociedades contemporâneas demandam a capacidade de compreender e seguir regras implícitas da cultura visual, as quais são desenvolvidas por meio de múltiplas, heterogêneas e, frequentemente, efêmeras imagens.

A difusão da cultura visual também se transformou: "As imagens hoje circundam o globo em padrões descentrados que permitem um acesso sem precedentes, deslizando-se quase sem restrições ao atravessar barreiras linguísticas e fronteiras nacionais" (BUCK-MORSS, 2004, p. 2). Contudo, esses padrões são produzidos dentro de interações globais que são, por sua vez, "amplamente desiguais em relação às capacidades de produção e efeitos reprodutivos" (BUCK-MORSS, 2004, p. 2).

Devido a essas dinâmicas, e seguindo o pensamento de W. T. J. Mitchell, é relevante considerar a cultura visual contemporânea não como um todo homogêneo e bem definido, mas sim como um conjunto de hipóteses

que necessitam ser comprovadas, por exemplo, que a visão é (como dizemos) uma construção social, que é aprendida e cultivada, não simplesmente dada pela natureza; que deve, então, ter uma história relacionada com a história das artes, das tecnologias, dos meios e das práticas sociais de se apresentar em público e olhar e ser olhado; e (por fim) que está profundamente envolvida com as sociedades humanas, com a ética e a política, a estética e a epistemologia de olhar e ser olhado (MITCHELL, 2002, p. 166). ${ }^{2}$

A partir dessa perspectiva, os discursos visuais estão inseridos nas práticas sociais e as imagens não são apenas signos, representações ou símbolos iconográficos, mas também efeitos de uma rede na qual os sujeitos operam e a partir da qual, por sua vez, estão condicionados (MIRZOEFF, 2005). Tal noção de cultura visual como um conjunto de hipóteses está em consonância com a multiplicidade de perspectivas e enfoques utilizados para explorá-la, um fenômeno que W. J. T. Mitchell (1994) define como a "virada pictórica" na pesquisa em ciências sociais.

Neal Curtis explica:

Ainda que a ideia de "virada pictórica" resista a qualquer definição simples devido ao seu lugar em um amplo conjunto de preocupações teóricas e práticas que dizem respeito a imagens, palavras, discursos, visualidade, objetos, meios e instituições, destaca-se o fato de que, atualmente, as imagens conformam um ponto de peculiar atrito e incômodo intelectual que atravessa um amplo raio de campos de investigação (CURTIS, 2010, p. 11).

A virada pictórica nas ciências sociais tem se manifestado de diferentes formas: na análise fenomenológica da visualidade e da imaginação (VATTIMO, 1997; MIRZOEFF, 1998; 2005); na investigação de Foucault sobre os "microrregimes" (1986; 1993); na proeminência de articulações entre visualidade e cultura de massas na pauta de pesquisas de estudiosos da Escola de Frankfurt, bem como na aceitação crescente dos estudos acadêmicos sobre a cultura popular e os meios de comunicação (KELLNER, 1994); na análise das imagens que relacionam raça, classe e gênero no debate sobre primatologia de Donna Haraway (1989); nos estudos de McLuhan sobre os meios (1964); na exploração de Martin Jay sobre a desvalorização da visualidade nos trabalhos filosóficos mais importantes do século XX (1993); nos trabalhos de Paul Virilio questionando a logística e o impacto das novas tecnologias da representação e da informação (1994); no olhar oblíquo e ardiloso de Slavoj Zizek sobre a psicanálise e a cultura popular (1991); nas discussões realizadas por Jay Ruby acerca das possibilidades e limitações das etnografias visuais (2005).

Os efeitos da virada pictórica parecem ser mais limitados no campo da pesquisa em Educação. Alguns estudiosos/as iniciaram analisando criticamente temas e aspectos relacionados à cultura visual e educação. Podemos exemplificar destacando os trabalhos de Inés Dussel (2010) com seus estudos sobre a "educação do olhar", Joseph Tobin e seu grupo $(1991 ; 2009)$ com a utilização de vídeos em pesquisas de educação comparada. E ainda muito mais: Eric Margolis (1999; 2004; 2005) analisou o uso de fotografias na investigação educacional; Ian Grosvenor e colaboradores $(1999 ; 2000)$ utilizaram documentos fotográficos na investigação histórica; Robert Coles e Nicholas Nixon (1998) realizaram uma exploração fotográfica e textual colaborativa acerca da vida cotidiana; Diamond e Mullen (1999) exploraram as possibilidades de investigação a partir da arte e Claudia Mitchell (2011) pesquisou as possibilidades de desenvolver estudos 
visuais junto a comunidades marginalizadas. Além desses exemplos, encontramos pesquisadores que têm produzido projetos muito interessantes nos quais vários fenômenos associados com a cultura visual não só foram analisados, mas também incorporados à produção acadêmica, como no caso de Fischer (2006, 2008), Schwertner (2010), Cruder (2008; 2010), Dalton (1999), Dussel e Gutiérrez (2006), Ellsworth (1997), Maeroff (1998) e Prosser (1998; 2007).

Apesar desses ilustres e renomados esforços, a grande maioria dos pesquisadores que participa do campo da investigação educativa tem permanecido bastante receosa para incorporar fenômenos visuais e/ou imagens tanto como fonte de informação relevante quanto como objeto de estudo em si mesmas, para além do uso esporádico de algumas ilustrações como complementos decorativos em discussões acadêmicas. Já em 1998 John Prosser notava que a investigação que incorporava imagens era "subvalorizada e subaplicada" (1998, p. 97) e quase uma década mais tarde, Barone e Eisner (2006) afirmaram que até mesmo a investigação educacional baseada nas artes expressivas - que por definição deveria ser a área mais ligada ao visual - teria "principalmente caráter literário" (p. 95). Além disso, uma revisão sobre as principais revistas que publicam pesquisas e estudos em Educação comprova uma orientação incontestável: há uma quase completa desvalorização dos fenômenos visuais que atravessa tradições acadêmicas, orientações teóricas e métodos de investigação (FISCHMAN, 2001).

Tal desconfiança no terreno do visual parece estar associada a argumentos que expressam preocupações relativas a determinados aspectos: a falta de rigor epistemológico, a fragilidade de instrumentos metodológicos e a (supostamente) contraproducente influência de enfoques teóricos pós-estruturalistas e pósmodernos. Outra linha de suspeita sobre a cultura visual é desenvolvida por acadêmicos e intelectuais que duvidam do valor das imagens, especialmente das fotografias (TAGG, 1993), como ferramentas para produzir conhecimento mais preciso sobre a sociedade, porque as fotografias produziriam distorções da realidade. Estas preocupações sobre o uso da imagem como insuficiente metodologicamente e/ou profundamente carregada de manifestações ideológicas preconceituosas definem o papel da imagem na investigação educacional como um sinônimo de perda de qualidade e rigor intelectual (WELCH, 1999).

Deveríamos considerar que a comodidade, a familiaridade e o tradicional são aspectos importantes neste processo de não se aventurar nas pesquisas visuais. Como afirma Senior (2011), uma pesquisadora experiente nesta área:
Em grande parte, com cautela para evitar acusações de sofismo autoindulgente, o pesquisador social de cunho qualitativo tende a basear-se nos dispositivos mais convencionais ou tradicionais para contar uma história de investigação. Os pesquisadores renunciam à possibilidade de escrever/ler nas fendas e fissuras das linhas distintas e indistintas. E eu, como muitos investigadores qualitativos, me deixo seduzir facilmente pela familiaridade e comodidade das ferramentas convencionais que oferecem as palavras, tais como as citações ou relatos de entrevistas, para contar a história da investigação (p. 65).

O difundido ceticismo que diz respeito à relação entre palavras, números e imagens pode se traduzir na negação das imagens não apenas como ferramentas válidas na pesquisa educacional, mas também na cultura visual em geral. No campo específico da investigação educacional, esta orientação tem importantes implicações. A desconfiança nas imagens, o que Bruno Latour e Peter Weibel (2002) chamam de modelo iconoclasta, tem um antepassado distante, como os diálogos de Platão e a proibição de muitas religiões sobre a representação de tipos de imagens. Platão menosprezava as imagens em sua República porque eram apenas uma "cópia" e não podiam ser comparadas ao modelo original ideal. Contra os iconoclastas, Latour e Weibel avançam com a ideia de iconoclash (choque icônico), como a tensão produzida pelo antigo e persistente conflito entre os princípios da iconoclastia e da iconofilia. Latour e Weibel expressam essa tensão de forma simples e elegante: "Se as imagens são tão perigosas, por que as temos em demasia? Se são 'inocentes', por que provocam tantas e duradouras paixões? Tal é o enigma, a indecisão, o quebra-cabeças visual, o iconoclash" (LATOUR; WEIBEL, 2002, p. 18).

\section{AVANÇOS PARA UMA PERSPECTIVA ICONOCLASH NA PESQUISA EM EDUCAÇÃO}

Tal como se discutiu anteriormente, em particular as últimas décadas mostraram um notável crescimento da investigação visual. Reconhecendo que este crescimento não é homogêneo e leva em conta a existência de múltiplas perspectivas, gostaríamos de propor que tais pesquisas se aproximam da noção iconoclash de Latour e Weibel, ao mesmo tempo em que respondem à noção de W. J. T. Mitchell de "cultura visual" como um conjunto de hipóteses. Uma tendência comum a esses estudos é o reconhecimento de que nas sociedades contemporâneas estamos todos envolvidos em atividades visuais, como agentes visuais (MIRZOEFF, 2005). Independentemente de nossa capacidade de ver e sermos vistos, como agentes visuais somos sujeitos e objetos de discursos visuais que são constitutivos na construção de nossas subjetividades. 
Como expressa Nikolas Rose: “É através da promoção de um 'estilo de vida' difundido pelos meios de comunicação, pela publicidade e pelos especialistas através da obrigação de constituir sua vida mediante opções em um mundo de objetos e imagens autorreflexivas, que o sujeito moderno é governado" (1990, p. 256).

Contudo, o ato físico de ver a multiplicidade de materiais visuais aos quais os cidadãos modernos estão expostos requer não apenas interpretar, classificar, decodificar e recordar, mas também ignorar e esquecer a maior parte deles. Consumir e descartar imagens é parte crucial de nossas experiências visuais cotidianas, inclusive nas escolas.

As instituições educativas operam de acordo com as culturas visuais explícitas e implícitas que estão inscritas nas posições ideológicas, espaciais e temporais dos produtores e consumidores de imagens e nos processos culturais que permitem tanto manifestações visíveis quanto aquelas consideradas invisíveis para se tornarem inteligíveis. O ponto que aqui gostaríamos de destacar é que o ato físico de ver se constitui uma operação pedagógica.

A aparentemente interminável multiplicação de imagens e seus efeitos de saturação envolvem aprendizagem, solicitando a "educação do olhar" (DUSSEL; GUTIÉRREZ, 2006). Entender aquilo que não se vê, o que é visível e o que deveria permanecer invisível, praticar as posições espaciais e temporais de ser observado e de ser observador, são todas operações visuais complexas que limitam e ensinam o que é possível ver e deixar de ver. É importante reconhecer, como observa brilhantemente Inés Dussel (2010), que a profunda conexão entre a escolaridade e a cultura visual não é um fenômeno recente, mas está profundamente conectada com a origem das instituições pedagógicas:

A pedagogia moderna, representada por Pestalozzi e outros, enfatizou o valor da educação da percepção e dos sentidos em termos de distância objetiva. $\mathrm{Na}$ educação visual que se promovia, ver se equiparava a conhecer e crer. Não havia mediação nem opacidade no ato de ver; as diferenças eram consideradas anormais e patológicas. Não menos importante foi a participação das escolas na organização de um sujeito social, o espectador moderno, capaz de ser, ao mesmo tempo, imparcial (que implica separação, uma distância entre observação e ação, mediada pela reflexão) e comprometido, ou seja, dotado de investimento afetivo, sentimental ou emocional necessário para o compromisso político na esfera pública (DUSSEL, 2010, p. 93).

Incorporar a cultura visual ao campo da pesquisa em Educação envolve, dessa forma, seguir muito além do uso de fotos, desenhos e outras imagens como acessórios de moda, ilustrações meramente passivas em detrimento ao "superpoderoso" texto escrito. A incorporação crítica dos fenômenos da cultura visual, seja mediante a utilização e inclusão de tecnologias visuais para registrar dados, a participação de aspectos visuais de situações educacionais e culturais em estudos ou o uso de imagens gráficas (fotoensaio, historietas e filmes) no processo de comunicar os resultados de uma pesquisa, requer atenção ao contexto social. Como práticas sociais, os rituais escolares, rotinas e todo tipo de interações pedagógicas não podem operar independentemente de seus contextos sociais, sempre levando em conta situações do passado e ajudando a imaginar acontecimentos futuros (FISCHMAN, 2000).

Outra consideração importante para avançar em uma perspectiva iconoclash envolve reconhecer que, apesar de muitos entenderem as escolas pela perspectiva do panóptico foucaultiano, este particular regime visual também é complementado, cada vez mais, pelo modelo sinóptico de participação visual, no qual uma grande maioria observa as imagens de alguns poucos. Este regime sinóptico de participação visual não substitui e sim complementa o regime disciplinar do panóptico, descrito notavelmente por Michel Foucault em Vigiar e punir (1996). Barry King explica que, para Foucault, o panóptico se constituía em um disciplinamento do olhar:

Em sua encarnação literal, os prisioneiros são colocados em celas vigiadas constantemente a partir de um ponto central privilegiado. Nesta organização óptica, os observados são literalmente examinados em detalhe e, em nível psicológico, constantemente conscientes da possibilidade de serem observados a toda hora. Esta organização espacial, argumenta Foucault, simplesmente concretiza uma prática social mais difusa na qual uma relação sinóptica mais antiga de muitos observando poucos foi substituída por poucos observando muitos (KING, 2000, p. 28).

O aspecto que buscamos destacar é o fato de que as dinâmicas visuais dos regimes panópticos/sinópticos operam fortemente no processo pedagógico de educar o olhar. O sinóptico, ainda que não se contraponha ao panóptico, ao menos oferece uma capacidade de penetração. A Internet, por exemplo, contém ambas possibilidades: vigilância corporativa ou governamental das atividades dos usuários e, igualmente, cidadãos comuns (se possuem acesso à Internet) observando os poderosos, ricos e famosos, com propósitos banais (e, às vezes, nem tão banais assim). Contudo, a comparação entre a prisão e a sociedade espectadora deve ser, provavelmente, exagerada. A própria observação de Foucault de que os sujeitos do olhar do panóptico internalizam o olho do 
vigia sugere que a disposição para olhar os outros poderia ser resultado da experiência de ser visto (KING, 2000).

Uma vez que as instituições educativas exercem suas atividades dentro dos regimes sinóptico/panóptico, os/as investigadores/as da educação necessitam desenvolver ferramentas para explorar os discursos visuais que permeiam escolas e universidades. Vale a pena insistir que, não obstante a centralidade das imagens vis-à-vis no conceito de cultura visual, há uma relação imprescindível e necessária entre fenômenos visuais e outros vetores relacionados e complementares, tais como os aspectos verbais, auditivos, emocionais, físicos, intelectuais, espaciais e históricos. Entender a visualidade requer investigar tanto a percepção e a recepção de imagens como as condições culturais, sociais e econômicas que cercam os produtores e usuários das múltiplas culturas visuais.

Do mesmo modo, os processos de percepção e recepção não são atos passivos nem estão inteiramente determinados por convenções sociais e culturais. Tal como Buck-Morss (1989) assinala, a dialética de olhar o mundo visual não deveria ser tomada como simples ilustração, pois não são ideias apressadas que se apresentam fortuitamente (ou ainda maliciosamente) e se distribuem eletronicamente ou de forma impressa para facilitar e satisfazer o observador-leitor (a despeito do valor de semelhantes ações). Por razões similares, é importante reexaminar o postulado tradicional de que textos, palavras e imagens se reforçam mutuamente através de conexões fixas ou transparentes.

Diferentes investigadores (BERGER, 1972, 1980; SONTAG, 1977; TAGG, 1993; CHAPLIN, 1994; JENKS, 1995) vêm discutindo a noção de reforço entre imagens, textos e palavras e propõem, em seu lugar, a necessidade de compreender a relação entre tais elementos a partir de uma interação dinâmica. $\mathrm{O}$ dinamismo da interação reside na ausência de um significado fixo entendido como uma relação necessária que, em si, é autoexplicativa (MITCHELL, 2002). Tais preocupações críticas formam um discurso de muitas vozes que assinalam na direção de que as imagens gráficas são, nas palavras de W. J. T. Mitchell, "inevitavelmente convencionais e contaminadas por linguagem" e, por essa razão, "a dialética da palavra e da imagem parece ser uma constante na trama de signos que uma cultura tece ao redor de si mesma. O que varia é a natureza precisa do tecido, a relação do conjunto de fios e da trama" (1987, p. 43).

O sentido último e verdadeiro de uma imagem não pode ser alcançado sem levar em conta o contexto ou as circunstâncias de sua produção, circulação e recepção. O significado nunca é absolutamente arbitrário em qualquer texto ou imagem. As ideias de Buck-Morss são muito relevantes nessa discussão:
A alegação de que as imagens estão fora de contexto (contexto cultural, intenção artística, contextos prévios ou de qualquer tipo) não é válida. Lutar para voltar a relacioná-las com sua fonte não é apenas impossível (já que se produz um novo significado); é perder o que elas têm de poderoso, sua capacidade de produzir sentidos e não simplesmente de transmiti-los (BUCKMORSS, 2004, p. 23).

O que buscamos aqui destacar é que existe sempre uma tensão no par imagem/significado. Existe uma probabilidade hipotética de atribuir a uma imagem um infinito número de sentidos e significados, mas em nossas interações cotidianas cada imagem apresenta sempre restrições de sentido ou, de outro modo, não produziria sentido. A credibilidade e finalidade das imagens utilizadas em um projeto ou pesquisa não reside tanto no fato de elas refletirem verdadeiramente o passado e o presente, mas em como a materialidade de cada imagem é conceitual e consistentemente marcada pelas perguntas que guiam um projeto de investigação.

\section{A IMAGEM DO MÉRITO. PARA QUE SERVE O SORRISO?}

Nos debates contemporâneos sobre os sistemas educativos, a mídia em geral - e a imprensa em particular - tem sido reconhecida como um ator de grande importância, pois constitui uma rica fonte de informações sobre ideias, tendências e problemas do setor educativo, mas também um espaço influente para pautar e confrontar os sentidos atribuídos a questões do campo (FISCHMAN; HAAS, 2011). Como afirmamos anteriormente, há muitos estudos sobre a importância da mídia, mas estudos sobre as imagens como um modo discursivo em particular, não são muito frequentes. Neste trabalho analisamos as imagens sobre universidade em artigos publicados pela revista Veja no período de 1995 a 2010. A escolha da Veja se justifica por ser uma das revistas semanais de grande circulação no país, parte de um conglomerado midiático de grande influência, por ser geralmente percebida como sendo politicamente influente e, ainda, por se auto-apresentar como se fosse ideologicamente equilibrada e não partidária.

Para serem compreendidos pelos/as leitores/as, os artigos das revistas semanais, tanto os textos como as imagens, devem refletir representações, entendimentos e ideologias geralmente aceitas pelos leitores (ALLAN, 1999; COTTER, 2000; FAIRCLOUGH, 1995a, 1995b; LAKOFF, 2008; LAKOFF; JOHNSON, 2003). O formato abreviado dos artigos limita a possibilidade de explicações detalhadas necessárias para comunicar informações menos conhecidas ou difíceis, inclusive protótipos não familiares (FAIRCLOUGH, 1995a, 1995b) e por isso as fotografias são tão importantes. 
Além da mera compreensão, a mídia tem que usar uma linguagem (escrita e visual) dentro do que se percebe como entendimento médio e tolerância pública a fim de manter o interesse da audiência e os lucros de propaganda (HERMAN; CHOMSKY, 1988; MCCHESNEY, 1999). Portanto, a mídia geralmente mantém e repete os entendimentos amplamente estabelecidos pelo seu público (ALLAN, 1999; VAN DIJK, 1988a, 1998b).

No presente trabalho analisamos as imagens visuais (fotos ou representações pictóricas) que foram publicadas em artigos relacionados à temática de Ação Afirmativa (AA) na Veja no período de 1995 a 2010 (quadro abaixo). Este grupo de nove artigos é parte de um grupo maior de 155 artigos relacionados ao tema "universidade". Neste caso em particular, procuramos entender por que dois tipos de representações (fotos de prédios ou de pessoas) foram sistematicamente utilizadas nestas revistas, quando a temática era AA.

Antes de analisar as imagens sobre AA, apresentamos os parâmetros gerais desta pesquisa. $\mathrm{O}$ primeiro que consideramos importante colocar é que o baixo número de artigos publicados por Veja sobre "educação" e "universidade" - em um universo de aproximadamente 30 mil artigos - indica que essas temáticas não parecem ser muito relevantes ou problemáticas para essa revista e seus leitores. Em um trabalho anterior (FISCHMAN; SALES, 2012), onde analisamos o discurso-texto das revistas semanais, assinalamos que parece ser muito provável que a classe média brasileira, leitora da Veja e Isto $E$ com a qual estas buscam dialogar e, em última instância, vender seu produto, não esteja muito "preocupada" com a universidade. Sabemos que a construção de qualquer assunto como "notícia" ou questão de "interesse público" requer a identificação de problemas.
Poucas notas sobre uma temática não indica ausência de "problemas" reais numa sociedade, mas é uma boa indicação sobre o nível de preocupação de um setor social e as publicações que a ele servem. A nossa análise mostrou que os leitores das revistas pareciam não ter maiores preocupações sobre a universidade em comparação com outras temáticas como drogas, trabalho e violência. Como grupo leitor das revistas, a classe média brasileira não mostrou interesse em leituras que questionem a universidade como instituição de ensino ou problematizem a educação de seus filhos/as.

Nas poucas notas relativas à universidade, uma das temáticas mais recorrentes foi a noção do "mérito", em particular na sua relação com uma série de artigos sobre AA, que é o foco deste artigo. Apesar de iniciativas de avaliação institucional em curso, é bem conhecido e pesquisado que a educação superior brasileira, em especial nas universidades públicas, é um sistema onde a ideia do "mérito", especificamente o mérito acadêmico baseado em desempenho escolar, está aferida historicamente por políticas de acesso e colocada como garantia para a qualidade do ensino (WEBER, 2010; SALES, 2007; MOEHLECKE, 2004). A importância dessa noção em relação com os debates sobre AA não pode ser minimizada, já que o "mérito" acadêmico da pessoa é um indicador social que representa o nível de talento e esforço individual. Usar um sistema baseado no mérito acadêmico aparece como uma política "justa" e "legítima" de distribuir um bem social escasso, como é o acesso à universidade pública. Neste caso a principal beneficiária desta noção de mérito acadêmico é a classe média brasileira que tem acesso às universidades públicas do país, especialmente nos cursos mais disputados.

\begin{tabular}{|c|c|c|l|l|}
\hline \multicolumn{5}{|c|}{ REVISTA VEJA - IMAGENS SOBRE ENSINO SUPERIOR EM AA* } \\
\hline 28 jul. 1999 & 1608 & $46-47$ & Lugar marcado & \multicolumn{1}{c|}{ Descrição das imagens } \\
\hline 26 fev. 2003 & 1791 & $70-71$ & Não deu certo & $\begin{array}{l}\text { Duas imagens com dois estudantes negros sérios } \\
\text { Quatro imagens com três estudantes brancos sérios e uma } \\
\text { estudante negra sorridente }\end{array}$ \\
\hline 19 mar. 2003 & 1794 & 20 & As cotas e a história nacional & Uma imagem com um estudante negro sorridente \\
\hline 21 abr. 2004 & 1850 & $75-76$ & Retrato em preto-e-branco & $\begin{array}{l}\text { Quatro imagens. Uma imagem do ministro de educação } \\
\text { sério e três imagens de estudantes brancos sérios }\end{array}$ \\
\hline 26 maio 2004 & 1855 & 20 & A maquiagem do monstro & $\begin{array}{l}\text { Uma imagem com uma caricatura do monstro } \\
\text { universitário }\end{array}$ \\
\hline 24 nov. 2004 & 1881 & 159 & Ovo neles, tomate neles! & Não tem imagens \\
\hline 26 jan. 2005 & 1889 & $48-51$ & O grande salto para trás & $\begin{array}{l}\text { Duas imagens: uma de estudantes trabalhando e outra de } \\
\text { um estudante negro sorridente }\end{array}$ \\
\hline 19 out. 2005 & 1927 & $63-64$ & Cotas sim, mas com mérito & Uma imagem de estudantes trabalhando \\
\hline 06 jun. 2007 & 2011 & $82-88$ & $\begin{array}{l}\text { Eles são gêmeos idênticos, } \\
\text { mas segundo UNB, este é } \\
\text { branco... este é negro }\end{array}$ & $\begin{array}{l}\text { Seis imagens de “negros famosos", sendo quatro } \\
\text { sorridentes }\end{array}$ \\
\hline
\end{tabular}

* Gostaríamos de poder apresentar as imagens analisadas, mas não é possível por não termos autorização da Editora Abril que publica a Veja. 
Assim, políticas ou ações que poderiam questionar a noção do "mérito" em relação ao acesso à educação superior no Brasil, tais como sistemas de acesso diferenciados, programas de AA, ou mesmo políticas de ampliação das vagas nas universidades públicas, tiveram uma forte repercussão na classe média brasileira e, consequentemente, na mídia que elas consomem. A revista Veja não foi uma exceção e, via de regra, alegou que as políticas de acesso diferenciado, as AA, e as políticas de ampliação, eram ameaças a um sistema baseado em "mérito" com consequências certas de queda na qualidade do ensino oferecido. A análise dos artigos demonstra que houve predominância da tensão "acesso" a educação e "qualidade". Nessa revista, as ideias de "acesso" e "qualidade" da educação aparecem como contradições, ou seja, como lados opostos em disputa em um jogo onde há ganhadores e perdedores. Nesse contexto, mais acesso significa menos qualidade ou mais qualidade requer restrições no acesso. ${ }^{4}$

Para resumir as conclusões da nossa pesquisa sobre os textos publicados na Veja com respeito as AA, é importante considerar que a revista trabalha com três tipos de lógica argumentativa: (1) quando AA era apenas uma "ideia" que poderia acontecer, não problematizava a noção de mérito e a revista não discutia a existência de problemas raciais no Brasil; (2) quando AA se transforma em política pública, passa a ameaçar a noção de mérito dentro da universidade e, além disso, se constitui em uma "solução errada", pois ela se propõe a resolver um problema que não existe, o racismo no Brasil; (3) quando AA se consolida como política pública e não é mais possível indicar que a sociedade brasileira é imune a problemas raciais, estas políticas são atacadas, porque vão gerar uma crise que afeta a noção de mérito e, além disso, são ineficazes por serem medidas demagógicas.

Nos textos analisados, a noção de mérito, claramente idealizada e desracializada, é sempre a melhor solução para resolver a contradição entre "acesso" e "qualidade" na educação superior. Agora, como é possível representar a noção de mérito em imagens? Mais especificamente, como foi representada visualmente a noção de mérito na Veja?

O primeiro ponto a destacar é que as imagens sobre universidade nesta revista são muito simples e podem ser classificadas em dois grandes grupos: (a) arquitetônicos (campus, edifícios ou prédios universitários); (b) pessoas.

Uma das características mais marcantes da contradição acesso/qualidade, expressa na Veja e que se apresenta como um elemento unificador das imagens, é a ideia de que o aumento potencial dos/as aluno/as afro-brasileiros/ as nas universidades públicas brasileiras vai desencadear uma crise no sistema meritocrático. A ideia da "crise" da educação superior (na forma de crise da universidade pública, crise de qualidade, crise de financiamento, crise na profissão docente) foi amplamente utilizada para tentar explicar o que aconteceria se o critério de mérito fosse afetado.

Mas como representar a crise da universidade brasileira que supostamente não está em crise? Como já indicamos, as imagens são de dois tipos: de prédios ou de pessoas. Neste artigo não vamos desenvolver a questão dos prédios, mas apenas indicar que estão divididos entre imagens de universidades clássicas "Ivy League" dos EUA (Harvard, Stanford, Princeton etc.) e as nacionais (USP, Unicamp etc.).

A sequência de fotos das matérias sobre AA tem uma peculiaridade. As fotos de estudantes brancos/as mostram rostos sérios, sem sorriso, enquanto as fotos dos/as estudantes negros/as mostram rostos sorridentes. ${ }^{5}$ Como esta estratégia de representação se repete em várias matérias em um período de mais de 16 anos, podemos descartar a ideia da casualidade. Como entender a importância do sorriso em relação com as AA e a ideia do mérito na universidade brasileira? É importante lembrar que os textos dos artigos enfatizavam a ideia da ausência de conflito racial e a necessidade de manter o sistema meritocrático. A contraposição dos rostos sérios/ sorridentes parece indicar que de fato existe um conflito racial, ponto que no texto era minimizado.

O sorriso é umas das características mais notáveis dos retratos modernos e a sua presença/ausência é indicativa da intencionalidade da revista em relação às dificuldades de manter um discurso sobre AA que revele tensões e contradições, fundamentalmente entre a escrita, que nega situações e promove soluções fundadas em argumentos que apelam a critérios supostamente mais objetivos e racionais, e a linguagem das imagens que, por apelar emocionalmente a interpretações mais abertas, escapa a significados mais fixos.

É necessário entender a tensão entre a familiaridade e a estranheza simultâneas para entender como a Veja caracteriza as imagens sobre universidade, escolhendo a presença do sorriso negro e a falta de sorriso branco para representar o que o texto afirma e as imagens negam ao mesmo tempo.

Em nossa opinião, a dinâmica texto/imagem sobre AA na Veja enfatiza áreas de conflitos sociais e educativos, profundamente influenciados pela dinâmica racial, com um toque irônico: a escrita nega, a imagem mostra. As imagens/palavras de Veja não oferecem uma versão única, unificada, sem contradições sobre as universidades brasileiras em relação à ideia do mérito e AA. Estas imagens com rostos sérios ou sorridentes resistem a ser simplificadas, ainda que elas sejam muito simples e capturem, com bastante precisão, a ambivalência da revista Veja e de seus leitores sobre a universidade em relação com o potencial transformador das AA. 


\section{CONSIDERAÇõES FINAIS}

Em resumo, o principal objetivo destas afirmações não é tanto um exercício de análise estruturalista nem tem a intenção de revelar um ponto cego na história da pesquisa educacional. Trata-se de um esforço para contribuir ao debate entre a iconoclastia e a iconofilia na investigação pedagógica, apresentando dois pontos básicos: primeiro, a constatação da ausência substancial dos fenômenos da cultura visual na pesquisa pedagógica, bem como o entendimento de que a subutilização das ferramentas metodológicas da pesquisa visual não se sustenta em barreiras epistemológicas; segundo, a pesquisa de fenômenos educativos a partir de uma perspectiva do iconoclash coloca novos problemas - tanto conceituais quanto metodológicos - e não oferece todas as respostas aos desafios que supõem compreender os regimes visuais que intervêm nas operações pedagógicas contemporâneas. Mas é um excelente ponto de partida e é epistemologicamente mais rigoroso e produtivo do que o enorme esforço que supõe a invisibilização do visual.

\section{REFERÊNCIAS}

ALLAN, Stuart. News culture. Buckingham, UK: Open University Press, 1999.

BARONE, Tom E.; EISNER, Eliot. Arts-based educational research. In: GREEN, J. L.; CAMILLI, G.; ELMORE, P. B. (Ed.). Handbook of complementary methods in education research. Mahwah: Lawrence Erlbaum, 2006. p. 95-109.

BERGER, John. Ways of seeing. New York; London: Penguin, 1972.

BERGER, John. About looking. New York: Vintage Books, 1980.

BUCK-MORSS, Susan. The dialectics of seeing: Walter Benjamin and the Arcades Project. Cambridge, Mass: MIT Press, 1989.

BUCK-MORSS, Susan. Visual studies and global imagination. Papers of Surrealism, v. 2, 2004. Disponível em: <http://www. surrealismcentre.ac.uk/papersofsurrealism/journal2/>. Acesso em: 19 maio 2013.

CHAPLIN, Elizabeth. Sociology and visual representation. London: Routledge, 1994.

COLES, R.; NIXON, N. School. Toronto: Little, Brown and Company, 1998.

COTTER, C. Discourse and media. In: SCHRIFFRIN, D.; TANNEN, D.; HAMILTON, H. E. (Ed.). The handbook of discourse analysis. Oxford, England: Blackwell, 2000. p. 416-436.

CURTIS, Neal. The pictorial turn. London: Routledge, 2010.

CRUDER, Gabriela. La educación de la mirada: sobre los sentidos de la imagen em los libros de texto. Buenos Aires: Stella - La Crujía, 2008.

CRUDER, Gabriela. Fotografía de un secreto. Question, v. 1, n. 25, 2010. Disponível em: <http://www.perio.unlp.edu.ar/ sistemas/ojs/index.php/question/article/view/894/795>. Acesso em: 18 out. 2011.

DALTON, Mary. Hollywood curriculum: teachers and teaching in the movies. New York: Peter Lang, 1999.

DIAMOND, C. T. P.; MULLEN, C A. (Ed.). The postmodern educator: arts-based inquiries and teacher development. New York: Peter Lang, 1999.

DUSSEL, Inés. Education and the production of global imaginaries: a reflection on teachers' visual culture. In: POPKEWITZ, T.; RIZVI, F. (Ed.). Globalization and the study of education. Chicago: NationalSociety for the Study of Education, 2010. p. 89-110 (108 Yearbook, v. 2).

DUSSEL, Inés; GUTIERREZ, Daniela. Educar la mirada: políticas y pedagogías de la imagen. Buenos Aires: ManantialFLACSO-OSDE, 2006.

ELLSWORTH, Elizabeth. Teaching positions: difference, pedagogy and the power of address. New York; London: Teachers College Press, 1997.

FAIRCLOUGH, Norman. Media discourse. London: Arnold, 1995a.

FAIRCLOUGH, Norman. Critical discourse analysis: the critical study of language. Harlow, UK: Longman, 1995b.

FISCHER, Rosa Maria B. Televisão \& educação: fruir e pensar a TV. Belo Horizonte: Autêntica, 2006.

FISCHER, Rosa Maria B. Mídia, juventude e educação: modos de construir o "outro" na cultura. Arquivos Analíticos de Políticas Educativas, v. 16, n. 1), 2008. Disponível em: <http:// epaa.asu.edu/epaa/v16n1>. Acesso em: 18 out. 2011.

FISCHMAN, Gustavo E. Imagining teachers: rethinking gender dynamics in teacher education. Landham, MD: Rowman and Littlefield, 2000.

FISCHMAN, Gustavo E. Reflections about images, visual culture and educational research, Educational Researcher, v. 30, p. 28-33, 2001.

FISCHMAN, Gustavo E.; HAAS, Eric. Nostalgia, emprendedorismo y redención: modelos discursivos sobre la universidad. Revista Iberoamericana de Educación Superior, v. 2, n. 3. 2011. Disponível em: $<\mathrm{http}: / /$ ries.universia.net/index. php/ries/article/view/86>. 2011. Acesso em: 20 out. 2012.

FISCHMAN, Gustavo E.; SALES, Sandra Regina. É possível ir além da disputa acesso-qualidade? O discurso sobre a universidade na Veja e na Isto É (1995-2010). Leitura: Teoria \&Prática, suplemento 58, jun. 2012, p. 1072-1082.

FOUCAULT, Michel. Of other spaces. Diacritics, v. 16, p. $22-$ 27, 1986.

FOUCAULT, Michel. Space, Power and knowledge. In: DURING, S. (Ed.). The Cultural studies reader. London: Routledge. 1993. p. 134-141.

FOUCAULT, Michel. Vigiar e punir: história da violência nas prisões. Petrópolis: Vozes, 1996.

GROSVENOR, Ian; LAWN, Martin; ROUSMANIERE, Kate. (Ed.). Silences and images: the social history of the classroom. New York: Peter Lang, 1999.

GROSVENOR, Ian; LAWN, Martin; ROUSMANIERE, Kate. Imaging past schooling: the necessity for montage. The Review of Education/Pedagogy/Cultural Studies, v. 22, n. 1, p. 71-85, 2000. 
HARAWAY, Donna. J. Primate visions: gender, race, and nature in the world of modern science. New York: Routledge, 1989.

HERMAN, Edward; CHOMSKY, Noam. Manufacturing consent: the political economy of the mass media. New York: Pantheon Books, 1988.

JAY, Martin. Downcast eyes: the denigration of vision in twentieth-century French thought. Berkeley: University of California Press, 1993.

JENKS, Chris (Ed.). Visual culture. New York; London: Routledge, 1995.

KELLNER, Douglas. Media culture. London: Routledge, 1994.

KING, Barry. Being virtual: modularity as a cultural condition. Afterimage, v. 28, n. 2, 2000. Disponível em: <http://www. thefreelibrary.com/beingvirtual: modularity as a cultural condition.-a066241193>. Acesso em: 24 out. 2011.

LAKOFF, George. The political mind: why you can't understand $21^{\text {st }}$-century American politics with an $18^{\text {th }}$-century brain. New York: Viking, 2008.

LAKOFF, George; JOHNSON, Mark. Metaphors we live by. Chicago: University of Chicago Press, 2003.

LATOUR, Bruno; WEIBEL, Peter (Ed.). Iconoclash: beyond the Image. Wars in science, religion, and art. Cambridge, Mass.: MIT Press, 2002.

MAEROFF, Gene (Ed.). Imaging education: the media and schools in America. New York: Teachers College Press, 1998. p. 26-45.

MARGOLIS, Eric. Class pictures: representations of race, gender and ability in a century of school photography, Visual Sociology, v. 14, p. 7-38, 1999.

MARGOLIS, Eric. Looking at discipline, looking at labor: photographic representations of Indian boarding schools. Visual Studies, v. 19, n. 1, p. 72-96, 2004.

MARGOLIS, Eric. Liberal documentary goes to school: farm security administration photographs of students, teachers and schools. In: HOLLOWAY, D.; BECK, John. American visual cultures. London; New York: Continuum, 2005.

MCCHESNEY, Robert. Rich media, poor democracy: communication politics in dubious times. New York: The New Press, 1999.

MCLUHAN, Marshall. Understanding media: the extensions of man. Cambridge: MIT Press, 1964.

MIRZOEFF, Nicholas (Ed.). The visual culture reader: studying visual culture. New York: Routledge, 1998.

MIRZOEFF, Nicholas. Watching Babylon: the war in Irak and global visual culture. New York: Routledge, 2005.

MITCHELL, Claudia. Doing visual research. Thousand Oaks: CA, Sage, 2011.

MITCHELL, William John Thomas. Iconology. Chicago: University of Chicago Press, 1987.

MITCHELL, William John Thomas. Picture theory. Chicago: University of Chicago Press, 1994.

MITCHELL, William John Thomas. Showing seeing. Journal of Visual Culture, v. 1, n. 2, p. 165-181, 2002.

MOEHLECKE, Sabrina. Ação afirmativa no ensino superior: entre a excelência e a justiça racial. Educação e Sociedade,
Campinas, v. 25, n. 88, out. 2004. Disponível em: <http:// www.scielo.br/scielo.php?script $=$ sci arttext\&pid $=$ S0101$73302004000300006 \& \operatorname{lng}=$ pt\&nrm $=$ iso $>$. Acesso em: 19 maio 2013.

PROSSER, Jon (Ed.). Image-based research. London: Falmer Press, 1998.

PROSSER, Jon. Visual methods and the visual culture of schools. Visual Studies, v. 22, n. 1, p. 13-30, Apr. 2007.

ROSE, Nikolas. Governing the soul: the shaping of the private self. London: Routledge, 1990.

RUBY, Jay. The last 20 years of visual anthropology: a critical review. Visual Studies, v. 20, n. 2, p. 159-170, 2005.

SALES, Sandra R. Justificativas, acordos e tensões: políticas de ação afirmativa na universidade brasileira. 2007. Tese (Doutorado em Educação) - Faculdade de Educação, Universidade do Estado do Rio de Janeiro, Rio de Janeiro, 2007.

SCHWERTNER, Suzana F. Laços de amizade: modos de relacionamento jovem em tempos de conectividade digital. 2010. Tese (Doutorado em Educação) - Faculdade de Educação, Universidade Federal do Rio Grande do Sul, Porto Alegre, 2010 .

SONTAG, Susan. On photography. New York: Farrar-StraussGiroux, 1977.

SENIOR, Kim. Incorrigible and undisciplined lines in visual social research: ways of 'writing' and 'drawing' at the interstices. Access: Critical Perspectives on Communication, Cultural \&Policy Studies, v. 30, n 1, p. 57-70, 2011.

TAGG, John. The burden of representation: essays on photographies and histories. Minneapolis: University of Minnesota Press, 1993.

TELLES, Edward. Racismo à brasileira: uma nova perspectiva sociológica. Rio de Janeiro: Relume Dumará; Fundação Ford, 2003

TOBIN, Joseph; WU, David; DAVIDSON, Dana. Preschool in three cultures: Japan, China \& the United States. New Haven, CT: Yale University Press, 1991.

TOBIN, Joseph; HSUEH, Yeh; KARASAWA, Mayumi. Preschool in three cultures revisited. Chicago: University of Chicago Press, 2009.

VAN DIJK, Teun. News as discourse. Hillsdale, NJ: Lawrence Erlbaum, 1988a.

VAN DIJK, Teun. News analysis: case studies of international and national news in the press. Hillsdale, NJ: Lawrence Erlbaum, 1988b.

VATTIMO, Gianni. Beyond interpretation: the meaning of hermeneutics in philosophy. Stanford: Stanford University Press, 1997.

VIRILIO, Paul. The vision machine. Bloomington, Indiana: University of Indiana Press, 1994.

WEBER, Silke. Avaliação e regulação da educação superior: conquistas e impasses. Educação e Sociedade, Campinas, v. 31, n. 113, dez. 2010. Disponível em: <http://www.scielo.br/scielo. php?script $=$ sci_arttext\&pid $=$ S0101-73302010000400011\&lng =pt\&nrm=iso $>$. Acesso em: 19 maio 2013.

WELCH, Anthony. The triumph of technocracy or the collapse of certainty? Modernity, postmodernity, and postcolonialism in comparative education. In: ARNOVE, Robert; TORRES, 
Carlos A. (Ed.). Comparative education: the dialectic of the global and the local. Lanham, Ma: Rowman and Littlefield, 1999. p. 25-50.

ZIZEK, Slavoj. Looking awry: an introduction to Jacques Lacan through popular culture. London: Routledge, 1991.

\section{Notas}

1 Agradecemos a Suzana Feldens Schwertner pela colaboração com a tradução da parte introdutória deste artigo, incluindo as citações, além de comentários críticos sobre o texto.
2 Queremos agradecer a Inés Dussel por chamar atenção à perspectiva de Mitchell neste ponto em particular.

${ }^{4}$ Para uma discussão mais aprofundada sobre as limitações desta perspectiva ver Fischman e Haas (2011) e Fischman e Sales (2012).

5 Gostaríamos de destacar que somos favoráveis à autodeclaração no que diz respeito à identidade racial, o que não é possível neste artigo, devido às características do material analisado. Destacamos, ainda, que estamos adotando a classificação racial utilizada pelo movimento negro que, ao reunir as categorias preto e pardo utilizadas pelo IBGE, cria a categoria negro (TELLES, 2003).

Artigo recebido em julho 2014.

Aprovado em novembro 2014. 